\title{
ENCUESTA DE PERCEPCIONES SOBRE LA PANDEMIA COVID-19 \\ EN TEPOZTLÁN, MORELOS (MÉXICO)
}

\author{
SURVEY OF PERCEPTIONS ON THE \\ COVID-19 PANDEMIC IN \\ TEPOZTLAN, MORELOS (MEXICO)
}

\author{
Lourdes Arizpe \\ Centro Regional de Investigaciones \\ Multidisciplinarias UNAM Morelos \\ ixel2015@gmail.com
}

\section{Esaú Bello}

Universidad Autónoma de Morelos

97esaupiensa@gmail.com

Sara González

Centro Regional de Investigaciones

Multidisciplinarias UNAM Morelos

samcar@live.com.mx

\author{
Leopoldo Núñez \\ Centro Regional de Investigaciones \\ Multidisciplinarias UNAM Morelos \\ Inf@unam.mx
}

Isis Saavedra L.

Universidad Autónoma Metropolitana

unidad Xochimilco

isluna@correo.xoc.uam.mx

\begin{abstract}
This study about Tepoztlan, a town reknown for its Mesoamerican lineage and for its resilience, offers both a statistical analysis and an ethnographic account of the local people's reactions to the SARS-CoV-2 pandemic. The survey was conducted at the height of confinement for the pandemic on November 2020, based on a "convenience sample" -a non-probabilistic sampling technique that is cost-effective and fast in its application- chosen to ensure the safety of the three young Tepoztecan students who applied the questionnaires. The study of 117 people shows how different the groups are in terms of age, gender and educational level and how have reacted to economic hardships, loss of personal autonomy and educational and other difficulties during the pandemic.
\end{abstract}

Keywords: COVID-19 Survey, pandemic, emotional impact, social impact, Tepoztlán.

\begin{abstract}
Resumen
El presente estudio sobre Tepoztlán, Morelos, pueblo reconocido en la literatura antropológica por su linaje mesoamericano y su resiliencia, ofrece un análisis estadístico y testimonios etnográficos sobre el impacto social de la pandemia del SARSCoV-2. Se entrevistó a 117 personas en el punto más alto de confinamiento por la pandemia, en noviembre de 2020, bajo el método del muestreo por conveniencia, técnica de muestreo no probabilística seleccionada con el fin de minimizar los riesgos sanitarios para los tres estudiantes tepoztecos que aplicaron los cuestionarios. Los entrevistados proyectaron afectaciones, incertidumbres y experiencias diferenciadas según edad, sexo y niveles educativos.
\end{abstract}

Palabras clave: encuesta COVID-19, pandemia, impacto emocional, impacto social, Tepoztlán. 


\section{Introducción}

La pandemia del virus SARS-CoV-2 lanza un desafío a nuestra comprensión sobre el impacto social y el manejo epidemiológico; altera gran número de las convicciones sobre las que se basan las sociedades del siglo $\mathrm{XXI}$, sin embargo, nuestra tenacidad como seres humanos está creando nuevas formas de protección y sobrevivencia, así como nuevos términos, ahora más afinados y complejos, para abarcar esta inesperada circunstancia.

Así lo expresaron las personas entrevistadas en la Encuesta de percepciones sobre la pandemia de la COVID-19' en Tepoztlán, Morelos que se expone en este artículo; dicha encuesta fue realizada del 24 al 30 de noviembre de 2020 con un equipo de investigadores formados en la antropología, sociología, matemáticas y tres estudiantes de ciencias sociales oriundos de Tepoztlán.

Este artículo se escribió en febrero de 2021, cuando en el pueblo morían una o dos personas al día a causa del virus; constantemente, las campanas de las iglesias tañían su lamento y pasaban diariamente procesiones hacia el cementerio; a veces los ataúdes eran acompañados, con toda tristeza, por los compañeros de la comparsa de la danza de los Chinelos. Aún ahora, todavía no acaba de colocarse, en ninguna parte, la incredulidad por lo que está sucediendo.

En este contexto iniciamos un camino riguroso de investigación, buscamos datos cuantitativos acopiados a través de una encuesta -por edad, sexo y nivel educativo, deslinde vital precisamente por esas reacciones tan diferenciadas- realizada durante la pandemia. Cualquier política o programa destinado a mejorar la situación requiere de un conocimiento preciso, científico, que vaya más allá de interpretaciones generales (Mendenhall et al., 2010). Se añadieron a estos datos estadísticos las palabras de los propios entrevistados acerca de este fenómeno que es tan inesperado como inasible.

1 Con la expresión COVID-19 nos referimos a las complejas reacciones producidas por el virus SARS-CoV-2 en los individuos, en la modalidad actual de la pandemia.
Los datos cualitativos son sumamente importantes porque permiten entrever un primer piso de patrones sociales de interpretación que se están resquebrajando ante lo avasallador de los contagios y las muertes. De hecho, todos nos hemos vuelto actores de nuestro propio bienestar y porvenir, lo cual tendrá efectos decisivos en el manejo de la pandemia y en la política nacional.

Los entrevistados de Tepoztlán expresaron, principalmente, preocupación por las consecuencias de la pandemia, tanto en su trabajo como en la economía en general. También mostraron una gran incertidumbre acerca de la salud, las relaciones educativas y sociales y sus consecuencias hacia el futuro; algunas plasmaron una impresión inmediata de la experiencia propia y otras empezaron a formular nuevos vocabularios sobre la pérdida de la libertad de acción, la necesidad de socializar y la responsabilidad de no dañar a los demás.

Mientras, en el ámbito público circularon interpretaciones generales que quedan como una visión neutral que explica muy poco; lo que necesitamos saber es, por lo tanto, quién lo dice, cómo lo dice y comparar las expresiones de mujeres y hombres, de jóvenes, adultos y adultos mayores y relacionarlo con sus niveles educativos. Saber eso con precisión permite captar la dinámica de lo que ocurre, ya que cada opinión refleja una respuesta rápida que busca estrategias para situaciones precisas, de la misma manera que permite vislumbrar los caminos que se tomarán hacia el futuro.

La trayectoria de la pandemia muestra que la gente de Tepoztlán logró un control sanitario muy eficaz en las primeras etapas de su expansión. A ello contribuyeron las acciones ciudadanas de gente de los barrios, unidas a una eficaz labor del presidente municipal Rogelio Torres Ortega, pero surgió la tragedia humana; después de haber logrado difíciles pero efectivas negociaciones entre los barrios, los comerciantes, los hoteleros y los grupos dedicados a la defensa del entorno natural, después de haber conseguido, antes que otras comunidades aledañas, la doble vacunación para la gente mayor de 
Tepoztlán, hacia fines de abril del 2021, Rogelio Torres Ortega murió, arrastrado por la COVID-19. Queremos hacer un reconocimiento amplio a su labor. ${ }^{2}$

Tepoztlán cuenta con un linaje mesoamericano profundo, que, según diversos autores, abarca las culturas olmeca-xicalanca, xochicalca, tolteca, xochimilca y algo de colhua para conformar lo que se ha denominado una región de cultura tlahuica en el norte de Morelos. Su entereza cultural se forjó a través de una historia política y social que abarca movimientos revolucionarios, la construcción política de instituciones y la defensa de su reserva natural. La belleza de su paisaje refleja una posición geográfica que se califica en términos de las coordenadas planetarias, de ahí que se le denomine "valle mágico".

Esaú Bello, coautor de este artículo y oriundo de Tepoztlán, hace notar que este largo proceso de cambio tiene sus cimientos en el esfuerzo, unión y cooperación mutua de sus pobladores. Tenemos que mencionar a don Jesús Conde Rodríguez, quien con una visión futura del progreso fue buscando mejores oportunidades de vida para su pueblo, abrió las puertas de Tepoztlán al mundo entero, como lo hizo constatar en las siguientes líneas:

conociendo el espíritu cívico que anima a ustedes espero que el esfuerzo que la Nación ha puesto al brindar a Tepoztlán, la construcción de su carretera a Cuernavaca, les sirva de estímulo para seguir con entusiasmo empeñándose por mejorar las condiciones culturales y materiales de su pueblo. (Vázquez Conde, 2020: 102).

\footnotetext{
2 También queremos hacer patente la labor de Víctor Lara, gerente de la central camionera Ometochtli de Tepoztlán, así como de David Byles, presidente de la Alianza de Vecinos del Valle de Atongo, y Alicia Cravioto, tesorera de la Alianza. Antes de que se hicieran visibles los estragos de la pandemia, invitaron a varios de los autores de este artículo a participar en un seminario para los choferes de sus unidades sobre la urgencia de propiciar que sus usuarios hicieran uso del cubrebocas y de las medidas sanitarias contra la pandemia.
}

Hay que mencionar tambien la importancia de los estudios antropológicos que se han elaborado partiendo de una comunidad que reúne las características idóneas de un pueblo en constante movimiento y evolución, y que a lo largo de los años ha tenido cambios sustanciales y objetivos; un pueblo como Tepoztlán que, a principios del siglo XIX, basó sus actividades económicas en la agricultura y que se ha convertido en la actualidad en una comunidad ampliamente diversificada desde el punto de vista cultural.

Esaú Bello explica que a partir de la globalización y el neoliberalismo, mediante sus alcances, Tepoztlán está viviendo una transición constante hacia una comunidad moderna y turística pero manteniendo las raíces y matices de su legado histórico, creando un microuniverso de ideas y personajes. Es así como Oscar Lewis describió la evolución del pueblo y sus habitantes durante su periodo de investigación en 1948: "a medida que Tepoztlán se mueve cada vez más en la dirección del mundo moderno, va dejando atrás la lengua indígena, muchas de sus costumbres nativas, su autonomía local y las formas colectivas de los tiempos prehistóricos" (Lewis, 1960: 205). Hace notar que en la ultima década del siglo XX Tepoztlán vivió un movimiento social de resistencia civil, un hecho histórico en el que la fraternidad comunitaria y la democracia viva se hizo valer. La homogeneidad de los ideales del pueblo se antepuso a la construcción de un megaproyecto residencial y un club de golf en zonas naturales invaluables para la comunidad (1995-1997). Fueron estos ideales los que acentuaron la organización civil y pacífica del pueblo para frenar dicho proyecto, pese a todo el escenario negativo, la decisión del pueblo fue victoriosa después de casi tres años de lucha contra los grupos de interés que impulsaban este proyecto.

Asimismo, considera que esta fraternidad comunitaria y democrática revivió una vez más para hacer frente a un enemigo invisible que asola al mundo entero: la pandemia de la COVID-19. El pueblo y el gobierno en turno tomaron medidas contundentes para frenar el inevitable paso de la pandemia, 
permitiendo una lenta o casi nula aceleración en la curva de los contagios y evitando la pérdida de vidas humanas. Estas decisiones colectivas las podemos ver escritas en el libro de María Rosas donde dice:

pedimos que el progreso que se plantee se discuta en la comunidad, que no atente contra nuestro modo de vivir ni contra la historia y la ecología de Tepoztlán. Los tepoztecos no le tememos al futuro, y por esa razón actuamos de esta manera. Aquí no se le permite entrar a la imposición. Aquí vive la democracia, la justicia y la libertad. (Rosas, 1997: 24).

\section{La batalla contra la pandemia en Tepoztlán}

El municipio de Tepoztlán se encuentra ubicado al norte del estado de Morelos y tiene una extensión territorial de 242,646 km, que representa $4.89 \%$ de la extensión territorial del estado. De acuerdo al Censo de Población y Vivienda 2020 (Inegi, 2020), el municipio cuenta con una población de 54, 987 habitantes, cifra que representa $2.8 \%$ de la población de la entidad; del total son 28,145 mujeres y 26,842 hombres, representan $51 \%$ y $49 \%$ de la población total, respectivamente.

A partir de la pandemia, el pueblo de Tepoztlán tomó acciones contundentes debido a la inminente propagación del virus a principios de abril del 2020. Los pobladores de los diferentes barrios se organizaron para formar retenes en las entradas del pueblo, únicamente permitían la entrada de residentes que pudieran comprobarlo y negaban la entrada a cualquier otra persona. Esta organización pasó a manos del ayuntamiento en marzo y el retén se mantuvo hasta septiembre del mismo año. Tepoztlán se aisló del mundo y del turismo, lo que contribuyó a que los casos de contagios de la pandemia se mantuvieran a la baja.

Mientras tanto, el sector del comercio se detuvo durante estos meses; no había turismo a quien ofrecer productos o servicios y muchos negocios tuvieron que cerrar, otros se readaptaron y cambiaron sus giros por nuevos. En un principio, los comerciantes organizados en los tres gremios existentes acataron las disposiciones del ayuntamiento pero esto cambió en diciembre, después de fuertes presiones hacia la autoridad para no volver a cerrar el pueblo. Ahora estas áreas de comercio tienen la responsabilidad de proporcionar las medidas de salud e higiene en cada una de sus áreas.

Es importante mencionar que, entre abril y septiembre, la Dirección de Turismo del municipio creó el distintivo "empresa responsable", otorgado a los grandes hoteles y restaurantes que capacitaron a su personal en los protocolos de la nueva normalidad, esta medida sirvió inicialmente para reactivar la economía, limitando la entrada de turismo únicamente a quienes tuvieran su reservación en alguna empresa responsable; para septiembre, ya en semáforo amarillo, el turismo podía entrar al pueblo sin reservación, lo que desencadenó un desbordamiento de visitantes. Esto explica, en parte, el aumento de los decesos por Covid-19 a partir de noviembre, a lo que se añadió cierto comportamiento social particular de individuos y grupos, así como actitudes provocadas por arraigos culturales existentes.

Como en otras partes de México, la curva de contagios aumentó notablemente en enero de 2021, con la diferencia de que se trató sobre todo de hombres de 40 años aproximadamente y de que los decesos sobrevinieron muy rápidamente después de que brotaron los primeros síntomas de la enfermedad. La gráfica 1 muestra la evolución de la pandemia desde abril de 2020 hasta el 15 de marzo de 2021. En febrero de ese mismo año, el ayuntamiento de Tepoztlán publicó carteles pidiendo a los visitantes que se quedaran en su casa y anunció que, en acuerdo con los grupos forestales de Tepoztlán, quedaba prohibido, hasta nuevo aviso, realizar excursiones a las montañas para evitar incendios. 


\section{Gráfica 1}

\section{Casos de COVID-19 en Tepoztlán, Morelos, al 17 de marzo de 2021}

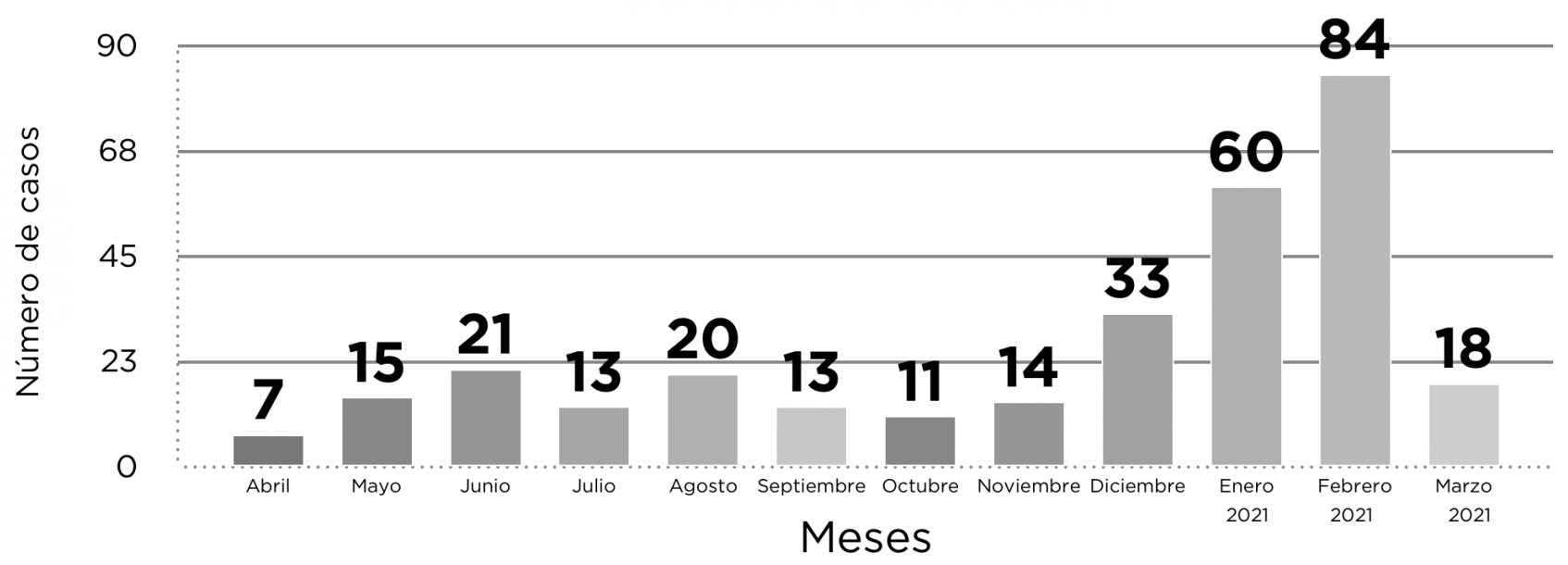

Fuente: elaboración propia con base en Gobierno de México (2021).

La gráfica 1 muestra una tendencia variable, pero con menos de 20 decesos mensuales de abril a noviembre, sin embargo, a partir de diciembre, prácticamente se duplicaron los casos mes con mes hasta febrero, con un descenso notable en marzo.

Es evidente que el aumento de casos en diciembre y enero se explica por la apertura de los retenes y la entrada de miles de turistas durante las fiestas navideñas y de principios de año, lo que corresponde a una continuación de las celebraciones culturales y de las reuniones familiares que no se alteró con la pandemia. Sin embargo, esta explicación ya no alcanza para comprender el aumento de casos en el mes de febrero.

Pensamos que ese aumento, posiblemente, se deba a dos tendencias: por una parte, a que el contagio del virus avanza en forma rizómica, es decir, como raíces que se insertan en otras raíces para crear un tejido denso de contagios, por otra, que durante las fiestas, algunos individuos de las familias se contagiaron y a lo largo de los dos meses siguientes, por la densidad de residencia de las familias, fueron contagiando a otros miembros de su familia inmediata, colateral o de afinidad. Esta hipótesis se apoya en el hecho de que en febrero hubo varios casos en los que murieron, casi al mismo tiempo, dos o tres hijos de una misma familia. En los estudios antropológicos, de hecho, ya sur- gió una línea de investigación sobre lo que se denominan "los contagios en las familias fuertes. ${ }^{3}$

\section{Encuesta de percepciones sobre la pandemia de COVID-19 en Tepoztlán}

Al proponer la realización de esta encuesta en noviembre de 2020 , pensamos que quizá sería el único momento en el que lograríamos aplicarla, puesto que los pronósticos sobre la pandemia, lejos de haber mejorado en los meses previos a noviembre se volvían cada vez más sombríos hacia el fin del año con la infinidad de fiestas por venir. En efecto, pocas semanas después, Tepoztlán, que había tenido comparativamente pocos casos de contagios en la primera parte de la pandemia, se enfiló hacia la tendencia general de semáforo rojo que se generalizó en Morelos y en casi todo México hacia finales de diciembre.

En marzo de 2020, por ejemplo, se sabía de otras muertes, pero todas ellas se atribuyeron a enfermedades específicas como afecciones del corazón, del riñón y otras a

3 Estos estudios se iniciaron con el seminario virtual Strong families and infection: European kinship and Coronavirus (Familias fuertes e infección: el parentesco europeo y el Coronavirus), en el que fueron ponentes Patrick Heady y Barbara Pieta, ambos del Instituto Max Planck para la antropología social (Heady y Pieta, 2020). 
las que se le dio poca atención, ya que no se había captado la comorbilidad con los casos de la COVID-19. Además, influyeron algunos de los rumores generados por los medios, pero sobre todo por las redes sociales como Twitter y Facebook, que insistían en que el virus no existía, que había sido elaborado en un laboratorio de China, que se trataba de una conspiración de los "Iluminati" para dominar el mundo, o que dentro de las inyecciones de la vacuna se insertarían "microchips" para controlar a las personas.

En esta Encuesta de percepciones sobre la pandemia COVID-19 en Tepoztlán se entrevistó a 117 personas, 15 de ellas se habían recuperado del virus en los diferentes meses previos. La encuesta la llevó a cabo un grupo independiente de investigación autofinanciado, en el marco de un estudio etnográfico más amplio, bajo la dirección de Lourdes Arizpe y la participación de Esaú Bello; colaboraron en su realización dos reconocidos especialistas en encuestas: Leopoldo Núñez y Sara González, la socióloga Isis Saavedra y dos estudiantes, Marlene Rojas e Iván Herrera.

El muestreo por conveniencia es la técnica de muestreo no probabilística más común, debido a su velocidad, costo-efectividad y facilidad de disponibilidad de la muestra. Con esta técnica se seleccionan las muestras por la disponibilidad que tienen para el investigador, tomando en cuenta condiciones difíciles o de peligro para los encuestadores. La encuesta de Tepoztlán se realizó durante un punto alto de la pandemia, atendiendo a la mayor protección posible de los escuestadores con el tiempo más corto posible de realización. Se aplicó este tipo de muestreo porque permitió un acceso rápido a los encuestados y porque, dadas las condiciones adversas, no se consideró seleccionar una muestra que represente a toda la población de Tepoztlán, pero que sí cumpliera con nuestra población de interés de personas mayores de 20 años, nativas, y que residieran en la comunidad.

La encuesta se planteó para 100 entrevistas, debido a los tiempos con que contába- mos para realizarla (siete días), el personal para el levantamiento (tres estudiantes) y el presupuesto. Se seleccionaron las calles de los barrios dónde hubo más enfermos, una vez ubicados se procedió a aplicar la entrevista casa por casa, al menos a uno de sus integrantes que cumplieran con las características de la población en estudio. Se hicieron 117 entrevistas.

La población de interés para la encuesta fue de personas mayores de 20 años, nativas, que residieran en esa comunidad, para realizarla se seleccionaron las zonas donde se sabía que hubo más enfermos durante un periodo de la pandemia y se seleccionaron calles en distintos barrios para realizar las entrevistas casa por casa, donde se encontraran personas que cumplieran los requisitos para ser entrevistados hubieran tenido o no el virus.

El equipo de investigación aplicó medidas extremas de desinfección y cuidado para que los tres jóvenes encuestadores, oriundos de Tepoztlán, tuvieran la mayor protección sanitaria al realizarla.

A los entrevistados se les aplicó un cuestionario para obtener sus principales características sociodemográficas y sus percepciones sobre el impacto y consecuencias de la pandemia en el presente y hacia el futuro. Como ya se mencionó, fueron entrevistadas 117 personas, 15 de ellas habían tenido Covid-19. Del total de entrevistas realizadas 51 fueron hombres y 66 mujeres; por grupos de edad se entrevistó mayoritariamente a personas de 20 a 35 años (29.1\%), seguido de los de 36 a 50 años (25.6\%), el grupo de 52 a 64 años representaba $23.9 \%$ y solo el $21.4 \%$ tenían 65 y más años de edad.

En cuanto a la escolaridad, sucede que a mayor escolaridad tenemos más entrevistados. Así, 33.6\% de los entrevistados estudiaron al menos un año de profesional, 24.1\% estudiaron al menos un año de la educación media superior (bachillerato/preparatoria), $23.3 \%$ cursó al menos un año de secundaria y solo 19\% estudiaron al menos un año de la primaria (Cuadro 1). 


\section{Cuadro 1}

Características sociodemográficas de los entrevistados

\begin{tabular}{|lll|}
\hline Sexo & Casos & Porcentaje \\
\hline Hombre & 51 & 43.6 \\
\hline Mujer & 66 & 56.4 \\
\hline Total & 117 & 100.0 \\
\hline Grupos de edad & Casos & Porcentaje \\
\hline $20-35$ & 34 & 29.1 \\
\hline $36-50$ & 30 & 25.6 \\
\hline $51-64$ & 28 & 23.9 \\
\hline 65 y más & 25 & 21.4 \\
\hline Total & 117 & 100.0 \\
\hline Escolaridad & Casos & Porcentaje \\
\hline Primaria & 22 & 19.0 \\
\hline Secundaria & 27 & 23.3 \\
\hline Bachillerato & 28 & 24.1 \\
\hline Profesional & 39 & 33.6 \\
\hline Total & 116 & 100.0 \\
\hline
\end{tabular}

Fuente: elaboración propia con base en la Encuesta de percepciones sobre la pandemia COVID-19 en Tepoztlán.

\section{"Todo cambió, la economía... la salud... la escuela... estar encerrados"}

Ahora se sabe que la COVID-19 puede afectar con distintos síntomas y consecuencias a cualquiera según la edad, el sexo y las enfermedades que la persona ya padezca: diabetes, obesidad e hipertensión, entre otras. Estas afectaciones, en términos sociales, también varían de acuerdo a la posición social, en relación con la desigualdad producida en las últimas décadas por las políticas neoliberales. Con este marco de referencia, la encuesta se orientó a captar las percepciones, los pensamientos y sentimientos de los entrevistados de distintos grupos ante este acontecimiento. Ante la pregunta en el cuestionario "¿Qué es lo que más le ha afectado de la pandemia?" (Cuadro 2), las respuestas de los entrevistados se concentraron en las siguientes percepciones:

\section{Cuadro 2}

Principales afectaciones que perciben los entrevistados por la pandemia

\begin{tabular}{|c|c|c|}
\hline Percepciones & Casos & Porcentaje \\
\hline $\begin{array}{l}\text { Cuestiones relacionadas con } \\
\text { su trabajo }\end{array}$ & 46 & 28.6 \\
\hline Perder libertad de acción & 25 & 15.5 \\
\hline Necesidad de socializar & 18 & 11.2 \\
\hline La economía en general & 18 & 11.2 \\
\hline Miedo, incertidumbre, estrés & 15 & 9.3 \\
\hline $\begin{array}{l}\text { Aumento de atención } \\
\text { en actividades escolares }\end{array}$ & 12 & 7.4 \\
\hline No le afectó & 11 & 6.8 \\
\hline Salud en general & 8 & 5.0 \\
\hline Otros & 8 & 5.0 \\
\hline Total & $161^{*}$ & 100 \\
\hline
\end{tabular}

*El número excede de 117, que son los entrevistados, debido a que se aceptaron hasta tres de sus respuestas y se sumaron para un total de 161.

Fuente: elaboración propia con base en la Encuesta de percepciones sobre la pandemia COVID-19 en Tepoztlán.

Hay que destacar que si sumamos "cuestiones relacionadas con su trabajo personal", que indica, por ejemplo, que la persona perdió el trabajo o tuvo que cerrar su comercio o tienda y "la economía en general", referida tanto a la de México como a la mundial, las respuestas representan $39.8 \%$, es decir, cerca de $40 \%$ del total de las respuestas (Cuadro 2). Resulta muy importante analizar estas respuestas comparativamente de acuerdo a si son varones o mujeres y según su grupo de edad, como se indica en el cuadro 3. 


\section{Cuadro 3}

Principales afectaciones por la pandemia, que percibieron los entrevistados, distribución porcentual según sexo y grupos de edad

\begin{tabular}{|c|c|c|c|c|c|c|c|c|c|c|}
\hline & & & lombre & & & & & Mujer & & \\
\hline Afectaciones & $20-35$ & $36-50$ & $51-64$ & $\begin{array}{l}65 \\
\text { y más }\end{array}$ & Total & $20-35$ & $36-50$ & $51-64$ & $\begin{array}{l}65 \\
\text { y más }\end{array}$ & Total \\
\hline $\begin{array}{l}\text { Aumento de atención } \\
\text { en actividades escolares }\end{array}$ & 30.0 & 0.0 & 11.8 & 0.0 & 12.5 & 12.9 & 0.0 & 0.0 & 0.0 & 4.1 \\
\hline $\begin{array}{l}\text { Aumento en las } \\
\text { actividades del hogar }\end{array}$ & -- & -- & -- & -- & -- & 3.2 & 2.8 & 0.0 & 0.0 & 2.1 \\
\hline $\begin{array}{l}\text { Cuestiones relacionadas } \\
\text { con su trabajo }\end{array}$ & 25.0 & 57.1 & 23.5 & 25.0 & 28.1 & 32.3 & 33.3 & 25.0 & 14.3 & 28.9 \\
\hline $\begin{array}{l}\text { Cuestiones relacionadas } \\
\text { con la salud }\end{array}$ & 15.0 & 0.0 & 0.0 & 5.0 & 6.3 & 6.5 & 11.1 & 0.0 & 7.1 & 7.3 \\
\hline La economía en general & 10.0 & 14.3 & 11.8 & 10.0 & 10.9 & 16.1 & 8.3 & 12.4 & 7.1 & 11.3 \\
\hline $\begin{array}{l}\text { Miedo, incertidumbre, } \\
\text { estrés }\end{array}$ & 5.0 & 14.3 & 5.9 & 10.0 & 7.8 & 3.2 & 13.9 & 6.3 & 28.6 & 11.3 \\
\hline Necesidad de socializar & 5.0 & 14.3 & 11.8 & 20.0 & 12.5 & 16.1 & 5.6 & 6.3 & 14.3 & 10.3 \\
\hline No le afectó & 0.0 & 0.0 & 17.6 & 20.0 & 10.9 & 0.0 & 5.6 & 6.3 & 7.1 & 4.1 \\
\hline $\begin{array}{l}\text { Perder libertad de } \\
\text { acción }\end{array}$ & 0.0 & 0.0 & 17.6 & 10.0 & 7.8 & 9.7 & 19.4 & 43.7 & 21.4 & 20.6 \\
\hline Otros & 10.0 & 0.0 & 0.0 & 0.0 & 3.2 & -- & -- & -- & -- & -- \\
\hline Total & 100.0 & 100.0 & 100.0 & 100.0 & 100.0 & 100.0 & 100.0 & 100.0 & 100.0 & 100.0 \\
\hline
\end{tabular}

Fuente: elaboración propia con base en la Encuesta de percepciones sobre la pandemia COVID-19 en Tepoztlán.

En general, los hombres jóvenes de 20 a 35 años respondieron que les afectó la pandemia por la disminución de sus ingresos económicos, tanto en su trabajo agrícola, como en sus empleos temporales o en su pequeño comercio. Uno de ellos expresó que le afectó de la siguiente manera: "en el campo, cuando la pandemia empezó nos llevó a la ruina. En mayo, toda la flor que sembramos la tiramos a la basura".

Otro joven, estudiante, ofreció todo un panorama al decir que lo que más le impactó fue "el desconocimiento de la situación, la desinformación de la peligrosidad de los posibles efectos del virus, el miedo... la desinformación mata, no sabe uno dónde actuar, qué acción tomar, con quien ir, que hacer, es muy desesperante". Un caso especial fue el de los tres hermanos repatriados de Estados Unidos por haberse enfermado de COVID-19. Al narrar lo que les ocurrió, uno de ellos dijo:

me afectó en mi trabajo que ya no pude terminar la jornada y no me pagaron completo. Casi casi nos corrieron de volada cuando les dieron los resultados de la prueba, y ahí la granja no nos quiso responder para el seguro médico porque nos pusieron muchas trabas y no se hacían responsables en caso de que alguien pueda morir y no ser repatriado a México. Me dio mucho coraje porque no nos dejaron defendernos y aquí pues no hay trabajo. 
En el caso de los hombres, predomina la preocupación por diversas afectaciones a su trabajo: $28.1 \%$, y su economía: $10.9 \%$, lo que arroja un total de $39 \%$; en sus propias palabras, uno de ellos respondió: "pues en la economía más que nada. Ya dejé de vender mi maíz en el mercado y pues nomás ando vendiendo a la del molino o así a las doñas que me encargan, pero está canijo, bajó mucho mi venta". Esta respuesta se complementa con la de otro entrevistado que expresó que el producto que siembra se devaluó, pues los insumos eran caros y ya no iba a poder sembrar más. Sin embargo, en el grupo de 30 a 35 años, un entrevistado mencionó que no le había afectado la pandemia, que dos familiares que estuvieron en los Estados Unidos tuvieron COVID-19 pero que ahora todo estaba bien. Este entrevistado destacó que la pandemia no le afecto, lo cual lo coloca entre el 10.9\% de la población que dijo no sentirse vulnerable ante la COVID-19.

Las respuestas de las mujeres contrastan con lo anterior, hacen muy evidente el desequilibrio en la división del trabajo por género, presentan mayores afectaciones en comparación con los hombres en las siguientes categorías: "cuestiones relacionadas con su trabajo personal" (28.9\%), "economía en general" (11.3\%), "perder libertad de acción" (20.6\%), "estrés, incertidumbre, miedo" (11.3\%) y "aumento de las actividades del hogar" (2.1\%).

Esta última percepción destaca ya que no la planteó ninguno de los hombres, además, se tiene que contextualizar en el hecho de que en la mayoría de las sociedades el trabajo doméstico ha sido históricamente delegado y naturalizado hacía las mujeres. Una de sus consecuencias fue el advenimiento de una cuádruple jornada que hoy se está exacerbando con la pandemia porque funde y cierra los tiempos entre las labores productivas, como las de reproducción social de las mujeres de todas las edades. Sin duda alguna, las mujeres muchas veces marcan la diferencia en la sobrevivencia de las familias en tiempos de pandemia.
En efecto, en el contexto de pandemia la combinación de jornadas de trabajo doméstico se ha intensificado: en las mujeres recaen las labores de desinfección, protección y cuidado de los enfermos, atender la educación académica de niñas y niños, quienes, dadas las circunstancias, no pueden asistir a la escuela, desinfectar una y otra vez, además de las tareas rutinarias domésticas. Todo ello además de llevar a cabo sus propios trabajos y tareas económicas en condiciones de precarización y desempleo. Esto se refleja en la encuesta en la categoría "perder libertad de acción", propuesta sobre todo por las mujeres, cuyos porcentajes totales, según sexo, fueron mayores en 12.8 puntos porcentuales a los de los hombres (20.6\% y $7.8 \%)$.

Las mujeres jóvenes que contestaron las preguntas de la encuesta expresaron sus pensamientos, percepciones y sentimientos. Una de ellas sintetiza lo que otras jóvenes expusieron con palabras vehementes:

Todo en mi vida diaria cambió, todo, desde las actividades académicas, culturales y de diversión. Dejé de frecuentar familiares, amigos. Ya no asisto a fiestas o reuniones. Y mi higiene personal, el uso de cubrebocas que detesto, aunque ya me estoy acostumbrando. En general creo que lo que más ha afectado es el hecho de estar encerrada, la incapacidad de poder hacer algo respecto a esta situación mundial, mis proyectos laborales.

Es evidente que la nueva participación educativa, económica y social de las jóvenes apoyada por los programas de gobierno y por las organizaciones feministas se ha visto coartada por el aislamiento. Es la edad en la que el papel de las mujeres se afianza en términos de adquirir un nivel educativo mayor que les permita participación social y política, relaciones de noviazgo y casamiento que influyen en su futuro, además de vinculación a través de las redes familiares.

La inesperada expansión de las actividades de reproducción social que llevan a cabo las mujeres hizo evidente que la salud y la sobrevivencia de sus familiares cae de 
Ileno en el terreno de ellas, esto se constata en las respuestas angustiadas de las madres jóvenes. Una, por ejemplo, expresó que está muy afectada por la pandemia en lo emocional y lo ve en especial en sus hijos al exclamar: "Ios está matando estar encerrados, y a toda la familia".

Así, con la pandemia, los avances de los jóvenes han quedado en espera, tanto para las mujeres como para los varones. En el caso de estos últimos el derrotero que expresan en sus preocupaciones se centra principalmente en los estudios y en la economía. Todos ellos, en conjunto, están activamente buscando razones y caminos para manejar la pandemia, pero no hay debates públicos en los que puedan participar para crear nuevos futuros adaptados a las condiciones de vida que se avizoran.

En cuanto a las mujeres de 51 a 64 años, 43.8\% (cuadro 3) manifestaron la pérdida de libertad de acción; sus percepciones se refieren a lo que expresan respecto a "no poder salir", ya sea a trabajar, a vender, a comprar víveres, a visitar a sus otros familiares. El impacto de estas restricciones, tal y como lo señalan, tiene consecuencias en muchas de ellas en "lo emocional".

Una de estas mujeres lo manifestó en los siguientes términos:

la situación es de temor. Nos comentó la doctora que nos da consulta que no sabe si eran de acá unas personas que tenían un enfermo en México de COVID, que se robaron el cuerpo y lo trajeron en el coche a Tepoztlán, lo tuvieron un rato por Xolalpa y luego lo metieron al panteón, quien sabe en dónde. Eso es un foco de infección, fue en la calle que se enfermaron muchos de COVID. Un niño de ocho años es el último que se enfermó, otros dicen que no está enfermo de COVID, otros que sí. Se murieron cuatro o cinco de COVID, (en esa calle) ya ni fueron al velorio.

Esta larga cita hace evidente el grado de falta de información veraz, precisa, así como las condiciones de abuso que han surgido durante la pandemia y la indefensión que sienten estas amas de casa y madres de familia. La compleja forma que toman las afectaciones por la pandemia -en las que un factor afecta otro, que a su vez afecta a otro- y se revierten así las consecuencias aumenta la incertidumbre.

Otra entrevistada, madre responsable de tres hijas, sin apoyo del esposo, expresa como le afectó: "lo de la escuela, el trabajo en línea es complicado. No hay recursos para el internet, el dinero de las copias... Hay el miedo de cuidarse. En la pandemia sí tenemos apoyo de 'Vamos Tepoz' mensualmente pero el miedo está para no acabar".

Durante el estudio también registramos diferentes tipos de programas para ayudar a la situación de las familias del municipio, tales como los programas de asistencia alimenticia con despensas y programas sociales que se entregaron en especie, por ejemplo: el programa para la producción de huevos criollos y de lechones para crianza, en los que se capacitaba a las mujeres en el desarrollo de estas dos actividades que tenían como objetivo garantizar alimentos de origen animal.

Para la mayoría de las mujeres de 51 a 64 años, a la pregunta de qué ha cambiado con la pandemia, la respuesta fue: "Todo". Una de ellas lo expresó con mucha lucidez al decir que el impacto de la pandemia se refleja en "la libertad de acción porque las cosas se realizan con temor, con el cuidado que si uno va a cruzarse con una persona, uno tiene el cuidado de no rozar con la persona, no tocar las cosas que no están en casa, es vivir con dudas".

Entre las mujeres de 65 años o mayores que respondieron a la encuesta, las cuatro respuestas se refieren a lo mismo. ¿Qué ha cambiado para ellas? Una de ellas respondió también: "Todo, estar encerrada, el estrés que no puedo salir, que nada más estamos adentro, tenemos miedo de contagiarnos y el dinero que no alcanza".

\section{"Tengo mucho miedo de volverme a contagiar"}

Fueron entrevistadas 15 personas que afirmaron haber tenido la enfermedad causada por la COVID-19. De los quince casos, $66.7 \%$ 
fueron hombres y $33.3 \%$ mujeres. Sobresale el hecho de que las entrevistas muestran que el contagio se concentró en las edades de los encuestados más jóvenes, es posible que esto indique el sesgo de los jóvenes encuestadores tepoztecos que entrevistaron a quienes sabían que habían tenido COVID-19, pues hasta ese momento en el pueblo se evitaba decir que alguien había sufrido la enfermedad (Cuadro 4). Quizá también indique que era dudosa la causa de la muerte de las personas de mayor edad que fallecieron en los primeros meses de la pandemia; se decía que su deceso había ocurrido por otras enfermedades, es decir, probablemente por la comorbilidad agravada por el virus.

\section{Cuadro 4}

Distribución porcentual de los entrevistados que han tenido COVID por sexo y grupos de edad

\begin{tabular}{lccccc} 
& \multicolumn{5}{c}{ Grupos de edad } \\
\cline { 2 - 6 } Sexo & $\mathbf{2 0 - 3 5}$ & $\mathbf{3 6 - 5 0}$ & $\mathbf{5 1 - 6 4}$ & $\mathbf{6 5}$ y más & Total \\
Hombre & 60.0 & 20.0 & 10.0 & 10.0 & 100.0 \\
Mujer & 60.0 & 40.0 & 0.0 & 0.0 & 100.0 \\
Sexo & & & & & \\
Hombre & 66.7 & 50.0 & 100.0 & 100.0 & 66.7 \\
Mujer & 33.3 & 50.0 & 0.0 & 0.0 & 33.3 \\
\hline Total & 100.0 & 100.0 & 100.0 & 100.0 & 100.0
\end{tabular}

Fuente: elaboración propia con base en la Encuesta de percepciones sobre la pandemia COVID-19 en Tepoztlán.

Con los testimonios de los entrevistados, que ya habían contraído la enfermedad de COVID-19, salió a la luz el desconcierto, lo que incluía en ese entonces a muchos médicos y enfermeras, que tuvieron que lidiar con un padecimiento que rebasó todos los parámetros anteriores de la medicina formal y tradicional. Lo señala una mujer del grupo de 35 a 50 años al expresar:

me puse mal y fui al centro de salud pero no me quisieron atender que porque tenía coronavirus, pero no era coronavirus, no podía ser coronavirus pues no salía de mi casa [...] era mi presión, me faltaba el aire, ya estaba enferma de taquicardia, tengo triglicéridos, las venas apretadas y me dieron un medicamento para quitar el estrés para que no me diera taquicardia.

Comentó también que era peligroso ir al hospital en Cuernavaca porque "allá esta lleno de COVID y si van allá, se van a contagiar". Parte del miedo a ir a hospitales, como nos lo comentaron otros entrevistados, era porque decían que los enfermos de COVID "entraban pero no salían" del hospital porque no entregaban los cuerpos; constatamos que corrían a toda velocidad toda clase de noticias falsas sobre los hospitales, algunas totalmente desorbitadas que, muy posiblemente, provenían de los medios y las redes sociales.

La mayoría de los contagios corresponden a personas que salen al trabajo, a sus estudios o al comercio, por ejemplo, tanto en Tepoztlán como en otros pueblos de la región se infectaron muchas personas que trabajaban en las centrales de abasto y en los mercados de Cuernavaca y Cuautla; en cambio, los campesinos dijeron que se sienten protegidos trabajando en el campo, si bien sí se infectaron los que producen cultivos comerciales, como ocurrió en el caso de los entrevistados que cultivan gladiolas.

En el caso de los menores de 35 años, en opinión de los propios enfermos de COVID-19 y de otros entrevistados, sufrieron el contagio por su resistencia a portar el cubrebocas, sobretodo los hombres jóvenes. De hecho, apenas en diciembre, empezó a generalizarse su uso entre los hombres y entre los jóvenes después de que el ayuntamiento mandó a la policía a exigir el uso del cubrebocas, incluso imponiendo una multa de 2 mil pesos a quien no lo usara, tanto a gente de Tepoztlán como a turistas.

Como lo indicaron las entrevistas, los síntomas y la propia trayectoria de los enfermos por COVID-19, al igual que en todo México y en el mundo, fueron muy variables en Tepoztán. Por una parte, los que tuvieron síntomas leves relatan experiencias como la siguiente: 
Pues sí, joven, casi cuando empezó lo de la pandemia tenía todos los síntomas de la enfermedad y pues sí nos dió miedo porque no quería enfermar a mi familia. Llamamos a la línea de atención [de los servicios de salud del gobierno] y... nos dijeron que eran casos sospechosos de COVID, así que me pidieron que no asistiera al hospital y que me mantuviera aislada de toda mi familia. La verdad fue bien difícil porque yo soy la que mantiene a mi familia. Tuvimos que recurrir a mis papás para que me ayudaran con mis hijos, porque no quería que se enfermaran. Pues ahorita ya no tengo ningún síntoma y pues creo que me fue bien porque no tengo secuelas

En cambio, otra mujer del grupo de 36 a 50 años, diabética, relata una experiencia muy dura:

Dicen que puede volver a dar COVID en tres meses, tengo mucho, mucho, miedo porque se siente muy feo. Hubo dos días en los que pensé que me iba a morir. Empezó con náuseas y dolor de cuerpo, primero fui a ver al médico y me dijo que no era COVID, luego ya no pude respirar, me tuvieron que poner oxígeno cuatro o cinco semanas. Ya no quiero volver a pasar por eso porque es muy caro, el oxígeno, radiografías, medicamento de mil para arriba, el médico me cobraba 8 mil la consulta cada semana y eso que me hizo descuento, pues es un conocido de la familia.

Caso aparte, ya mencionado en páginas anteriores, es el de los tres hermanos que se contagiaron de COVID-19 en los Estados Unidos trabajando como jornaleros en el campo $y$ que fueron repatriados inmediatamente por los dueños de la granja. Su regreso fue difícil, tal y como lo relata uno de ellos:

mi mamá nos comentó que nos querían sacar de la colonia a los tres que llegamos de Estados Unidos con COVID... eso me enojó mucho y no me iba a dejar, no sé quién o quiénes dijeron eso, se corrió el chisme luego luego. Mi familia tiene miedo todavía pues ya lo vivieron, fue difícil volver a una vida normal, por el miedo. La falta de compromiso de las perso- nas es algo negativo, que la gente no crea es negativo, a nosotros nos afectó pues fue mi caso, esto [el virus] no ha terminado.

También se incluyó una pregunta en la encuesta sobre las secuelas de la enfermedad del COVID-19. Este tema se empezó a discutir en la Organización Mundial de la Salud en agosto del 2020, cuando, a seis meses de haberse padecido la patología se hizo evidente que muchos enfermos seguían mostrando síntomas variables y difíciles de reconocer del COVID-19 (Grover y Sample, 2021). En Tepoztlán, apenas se empezaban a discutir las secuelas de la enfermedad, en noviembre 2020, cuando se realizó esta encuesta.

De los entrevistados que se contagiaron del virus, $46.7 \%$ dijo que tenía afecciones relacionadas con los pulmones, $20 \%$ mencionó un cansancio desmedido y $26.7 \%$ declaró que no tenía ya ningún síntoma de la enfermedad. Es interesante que los enfermos de más de 50 años señalaron únicamente que tenían dolores musculares y de huesos como secuelas, o que no tenían ningún síntoma persistente (Cuadro 5).

\section{Cuadro 5}

Principales secuelas de los entrevistados que tuvieron COVID, distribución porcentual por grupos de edad

\begin{tabular}{lccc} 
& \multicolumn{3}{c}{ Grupos de edad } \\
\cline { 2 - 4 } Secuelas & $\mathbf{2 0 - 5 0}$ & $\mathbf{5 0}$ y más & Total \\
$\begin{array}{l}\text { Enfermedades } \\
\text { relacionadas con } \\
\text { los pulmones }\end{array}$ & 53.8 & 0.0 & 46.7 \\
\hline $\begin{array}{l}\text { Cansancio } \\
\text { exagerado }\end{array}$ & 23.1 & 0.0 & 20.0 \\
$\begin{array}{l}\text { Ninguno } \\
\begin{array}{l}\text { Dolores musculares } \\
\text { y de huesos }\end{array}\end{array}$ & 0.0 & 50.0 & 6.6 \\
\hline \begin{tabular}{l} 
Total \\
\hline
\end{tabular} & 100.0 & $\mathbf{1 0 0 . 0}$ & $\mathbf{1 0 0 . 0}$ \\
\hline
\end{tabular}

Fuente: elaboración propia con base en la Encuesta de percepciones sobre la pandemia COVID-19 en Tepoztlán.

En el caso de quienes ya padecieron COVID-19 ¿cambiaron las actitudes de quiénes tuvieron la enfermedad del COVID-19 hacia la pandemia? Sí, ya que subió la preocupa- 
ción por la salud de $2.9 \%$ en los encuestados sin COVID a $17.4 \%$ en aquellos con COVID. Sus respuestas cambiaron ligeramente al bajar en relación con "perder la libertad de acción": $15.9 \%$ en los primeros y $13.1 \%$ en los segundos, pero es significativo que, como era de esperarse, la necesidad de socializar subió de $10.9 \%$ en los que no tuvieron COVID-19 a 13.1\% en los que sí se vieron afectados por el contagio (Cuadro 6).

\section{Cuadro 6}

Principales afectaciones por la pandemia que percibieron los entrevistados, distribución porcentual según si han tenido o no COVID-19

\begin{tabular}{lcc}
\hline Afectaciones & Sin COVID & Con COVID \\
\hline Ansiedad-depresión & 1.5 & 4.3 \\
\hline $\begin{array}{l}\text { Aumento de atención en } \\
\text { actividades escolares }\end{array}$ & 7.2 & 8.7 \\
\hline $\begin{array}{l}\text { Aumento en las actividades } \\
\text { del hogar }\end{array}$ & 1.5 & 0 \\
\hline $\begin{array}{l}\text { Cuestiones relacionadas con } \\
\text { su trabajo }\end{array}$ & 29.7 & 21.8 \\
\hline La economía en general & 12.3 & 4.3 \\
\hline Miedo, incertidumbre, estrés & 9.4 & 8.7 \\
\hline Necesidad de socializar & 10.9 & 13.1 \\
\hline No le afectó & 8 & 0 \\
\hline Perder libertad de acción & 15.9 & 13.1 \\
\hline $\begin{array}{l}\text { Preocupación de las malas } \\
\text { noticias en los medios }\end{array}$ & 0 & 4.3 \\
\hline Que se siga muriendo gente & 0.7 & 0 \\
\hline Repatriados & 0 & 4.3 \\
\hline Salud en general & 2.9 & 17.4 \\
\hline Total & 100.0 & 100.0 \\
\hline Fuente; & & \\
\hline
\end{tabular}

Fuente: elaboración propia con base en la Encuesta de percepciones sobre la pandemia COVID-19 en Tepoztlán.

\section{El futuro: "Me preocupa que no volvamos a conocer la vida y el mundo como era antes"}

En cuanto a las percepciones sobre el impacto de la pandemia de COVID-19 respecto al porvenir, la mayoría de los entrevistados proyectaron las afectaciones que han tenido en la actualidad hacia el futuro. Cabe mencionar que en este caso sí aumentaron los contrastes en las percepciones entre mujeres y hombres.
Del total de los hombres, 33\% mencionó la economía y las actividades relacionadas con el trabajo, pero sorprende que es mayor aún este porcentaje en el total de mujeres: $38.8 \%$ (Cuadro 7). Esto puede deberse, como lo indicaron las entrevistas, a que, por una parte, las mujeres se sienten más inseguras por volver a retomar sus propias actividades económicas o empleos más adelante y, por otra, al temor de que sus esposos puedan perder su participación económica, lo que recae adicionalmente en sus propias preocupaciones económicas.

El hecho que sobresale es que el tercer porcentaje más alto de sus inquietudes se refiere al aumento del trabajo en el hogar, $13.3 \%$, respuesta que está prácticamente ausente en el caso de los hombres, solo uno se refirió a este tema.

Otro contraste significativo es que, entre los hombres, la preocupación sobre la economía en el futuro tiene el mismo alto porcentaje que el de la salud, $20.5 \%$ en sus respuestas, tema al que se refieren muy pocas veces en las entrevistas más extensas. De hecho, en los meses iniciales de la pandemia fue notoria la fuerte resistencia de los hombres para acatar los llamados a utilizar el cubrebocas y a tomar precauciones de sana distancia contra los contagios. Las bromas eran constantes: "no me veo como hombre", decían mostrando que su masculinidad los lleva a expresar desdén por someterse a éstas y otras reglas. En contraste, solo $11.2 \%$ de las mujeres se refieren a la salud $y$, en cambio, manifiestan mayores inquietudes de "miedo, incertidumbre y estrés", 12.2\% (Cuadro 7).

Si se analizan estos datos por grupos de edad, se aclara aún más la dinámica de las percepciones; por una parte, 33\% del total de los hombres consideró en su respuesta consecuencias en la economía y en el trabajo a futuro; lo que, comparado especificamente con el grupo de edad de 20 a 35 años, en menor, pues la preocupación aumentó a $36.7 \%$; esto es más marcado aún en las mujeres, del total, $38.8 \%$ se preocupa por las consecuencias en la economía y trabajo a futuro y aumenta a $48.2 \%$ en el grupo de edad de 20 a 35 años. 


\section{Cuadro 7}

Principales consecuencias que perciben los entrevistados en el futuro, distribución porcentual por edad y sexo

\begin{tabular}{|c|c|c|c|c|c|c|c|c|c|c|}
\hline \multirow[b]{2}{*}{$\begin{array}{l}\text { Consecuencias } \\
\text { a futuro }\end{array}$} & \multicolumn{5}{|c|}{ Hombre } & \multicolumn{5}{|c|}{ Mujer } \\
\hline & 20-35 & $36-50$ & $51-64$ & 65 y más & total & 20-35 & $36-50$ & $51-64$ & 65 y más & total \\
\hline Ansiedad-depresión & 5.3 & 0.0 & 0.0 & 0.0 & 1.4 & 3.5 & 2.4 & 0.0 & 20.0 & 4.1 \\
\hline $\begin{array}{l}\text { Aumento en las actividades } \\
\text { del hogar }\end{array}$ & 0.0 & 9.1 & 0.0 & 0.0 & 1.4 & 13.8 & 17.1 & 11.1 & 0.0 & 13.3 \\
\hline $\begin{array}{l}\text { Cuestiones relacionadas con } \\
\text { su trabajo }\end{array}$ & 15.6 & 18.1 & 13.1 & 5.0 & 12.5 & 24.1 & 9.8 & 38.8 & 0.0 & 18.4 \\
\hline "Dios dirá" & 0.0 & 0.0 & 13.1 & 0.0 & 4.2 & -- & -- & -- & -- & -- \\
\hline La economía en general & 21.1 & 18.2 & 17.4 & 25.0 & 20.5 & 24.1 & 22.0 & 16.7 & 10.0 & 20.4 \\
\hline Miedo, incertidumbre, estrés & 5.3 & 9.1 & 13.1 & 20.0 & 12.3 & 6.9 & 12.2 & 16.7 & 20.0 & 12.2 \\
\hline Necesidad de socializar & 5.3 & 0.0 & 0.0 & 0.0 & 1.4 & 0.0 & 2.4 & 0.0 & 0.0 & 1.0 \\
\hline No le afectara en nada & 0.0 & 0.0 & 4.3 & 5.0 & 2.7 & 0.0 & 2.4 & 0.0 & 10.0 & 2.0 \\
\hline Perder libertad de acción & 5.3 & 0.0 & 4.3 & 15.0 & 6.8 & 13.8 & 9.8 & 0.0 & 0.0 & 8.2 \\
\hline $\begin{array}{l}\text { Preocupación de las malas } \\
\text { noticias en los medios }\end{array}$ & 0.0 & 0.0 & 4.3 & 5.0 & 2.7 & 0.0 & 0.0 & 0.0 & 10.0 & 1.0 \\
\hline $\begin{array}{l}\text { Que el gobierno no pueda } \\
\text { manejar la pandemia }\end{array}$ & 10.5 & 0.0 & 0.0 & 0.0 & 2.7 & 0.0 & 2.4 & 5.6 & 10.0 & 3.1 \\
\hline $\begin{array}{l}\text { Que no todos acaten las } \\
\text { medidas sanitarias }\end{array}$ & 5.3 & 0.0 & 0.0 & 5.0 & 2.7 & 0.0 & 4.9 & 0.0 & 0.0 & 2.0 \\
\hline Que se siga muriendo gente & 0.0 & 27.3 & 4.3 & 10.0 & 8.2 & 0.0 & 2.4 & 0.0 & 20.0 & 3.1 \\
\hline Salud en general & 26.3 & 18.2 & 26.1 & 10.0 & 20.5 & 13.8 & 12.2 & 11.1 & 0.0 & 11.2 \\
\hline Total & 100.0 & 100.0 & 100.0 & 100.0 & 100.0 & 100.0 & 100.0 & 100.0 & 100.0 & 100.0 \\
\hline
\end{tabular}

Fuente: elaboración propia con base en la Encuesta de percepciones sobre la pandemia COVID-19 en Tepoztlán.

Así, algunas mujeres de 51 a 64 años destacaron que lo que más les preocupa es "la economía en un futuro [porque] todo ya está subiendo, todo está caro, no hay trabajo...". Recalcan que "se encareció todo, los lugares cerraron, le subieron los precios en el centro [del pueblo] mucho más". Una de ellas fue más allá al expresar una visión apocalíptica: "va a haber robos, va a haber hambre, no vamos a tener que comer, va a haber muertes, más muertes, mientras no se tomen medidas sanitarias, va en cadena la influenza y el COVID...”.

Por su parte, en las entrevistas, los hombres de este mismo grupo de edad, 51 a 64 años, expresaron sus preocupaciones por el futuro en estos términos: "Temo el co- lapso de los pequeños negocios, la falta de empleo, la falta de medicinas", expuso uno de ellos. Otro lo resumió así: "Hemos perdido mucho trabajo... las personas ya no nos alquilan para trabajar; son más difíciles de cubrir los gastos de la casa porque muchas personas ya no quieren que vayamos a sus casas a trabajar por el miedo que hay de la pandemia".

Expresó una visión más amplia otro entrevistado al afirmar:

Muchas formas o costumbres de vida se van a modificar, y lo mismo en el aspecto laboral... muchos empresarios van a aprovechar la pandemia para desviar algún plan mercadológico, un plan de acción para que les vaya 
mejor en los negocios con el desempleo [...] los bajos salarios que sin la pandemia ya se veían afectados y con la pandemia se verán más afectados.

Se agrupan otras respuestas acerca de las consecuencias de la pandemia hacia el futuro en términos del impacto emocional y de rango de acción en torno a las respuestas que corresponden a "miedo, incertidumbre y estrés" y "perder la libertad de acción". De los hombres jóvenes $10.6 \%$ y el doble: $20.7 \%$, de las jóvenes de 20 a 35 años se refirieron a dichos "efectos emocionales" de la pandemia en cuanto a que piensan continuarán en el futuro.

Destacan los porcentajes de respuestas de las mujeres acerca de la perdida de libertad de acción y del aumento en las actividades del hogar: $13.8 \%$, mientras que los hombres del mismo rango de edad no se mostraron preocupados; para el total de las mujeres esta preocupación ocupa el tercer lugar con el $13.3 \%$ (Cuadro 7).

Otra tendencia visible en el Cuadro 7 es la que se presenta respecto a las consecuencias de la pandemia que preocupan a futuro; las respuestas sobre miedo e incertidumbre, y otras cuestiones emocionales, se exacerban en las personas mayores de 65 años. La excepción en estas respuestas proviene de las personas de esa edad que se encuentran jubilados o que reciben un ingreso otorgado por la Secretaría de Bienestar o el Instituto Nacional de las Personas Adultas Mayores (Inapam). Claro está que de todas maneras les angustian estos temas: "que mi familia pueda contagiarse y se mueran mis conocidos", "que no todos respeten las medidas de seguridad con la sana distancia y el cubrebocas". En cuanto a otras percepciones, en este grupo de edad, y en el caso de los hombres mayores, solo tres de ellos dieron la respuesta: "Dios dirá". Respecto al futuro, uno de ellos dijo: "eso es cosa del Señor, no sabemos, yo le pido a Dios que haga algo para todos, es obra de Dios, nosotros ¿qué podemos hacer?".

Para terminar esta sección sobre las percepciones de futuro a raíz de la pandemia, vale incluir completa la cita de una joven de 20 a 35 años que dijo, con gran sensibilidad:

me preocupa que no volvamos a conocer la vida y el mundo como era antes, ese constante temor de la muerte, la enfermedad, como te decía, medio mundo perdió su empleo y sus ganas de vivir, de salir, de conocer.

Es importante contraponer a esta percepción, la de un entrevistado mayor de 65 años, que afirmó que:

en el futuro hay que quedarnos en casa, como yo trabajo en el campo no hay tanto problema... los retenes fueron favorables porque viene mucha gente... hay que acostumbrarnos y cuidarnos, como es un virus puede llegar de todos lados, mejor protegernos para no lamentarnos.

Dice mucho este contraste en el que no podemos adentrarnos en este breve artículo, si bien hay que decir que apunta a lo que se mencionó antes, a la necesidad de crear políticas públicas que sean efectivas y que estén dirigidas a las preocupaciones específicas de mujeres y hombres de distintas edades.

\section{Conclusiones}

La batalla contra la pandemia provocada por el virus Sars-Cov-2 empezó en abril del 2020 en Tepoztlán, con los filtros sanitarios que instauraron los barrios y el ayuntamiento para restringir la entrada de visitantes a la comunidad. Ello permitió, a comparación de otros pueblos de la región, lograr que los decesos no rebasaran el límite de veinte casos mensuales. Durante ese tiempo el ayuntamiento creó el programa de "empresas responsables" acordado con los hoteles, hospedajes y comerciantes para permitir una entrada limitada de visitantes.

Sin embargo, a partir de septiembre, los filtros sanitarios dejaron de operar, tanto por la presión de los comerciantes, los hoteles y otros grupos económicos, así como por el sorpresivo aumento de visitantes que querían vacacionar al aire libre. 
Para tratar de dar orden a la ola de visitantes, entre otros programas, el ayuntamiento formó brigadas de guías que acompañaran a los visitantes en sus excursiones para evitar el deterioro al medio ambiente. Por otro lado, ya sin retenes, las fiestas de fin de año se celebraron, aunque con medidas sanitarias, en grande, lo que produjo que se duplicaran los decesos mensuales de diciembre a febrero. Las procesiones con flores, ataúdes y cubrebocas rumbo al cementerio sucedían una tras otra, la gente, como dijo una entrevistada, "ya ni [iba] a los velorios".

"Todo en mi vida diaria cambió..." es la frase que resume las respuestas de gran número de los entrevistados, sobre todo de las mujeres". En el caso de los hombres, predominó la preocupación por "cuestiones relacionadas con su trabajo personal", $28.1 \%$, y su economía, $10.9 \%$, lo que arroja un total de $39 \%$; sorprende que para las mujeres son equivalentes estas preocupaciones, con $28.3 \%$ y $11.3 \%$, que llegan a un total ligeramente mayor de 40.2\%. ¿Cómo explicar esta equivalencia cuando el supuesto convencional es que las mujeres solo se ocupan del hogar y de la familia?

Las entrevistas etnográficas muestran que la mayor inseguridad económica de las mujeres se refiere a que han sido afectadas en sus propios empleos en el mercado laboral, por ejemplo, en el empleo doméstico remunerado o en el comercio informal y que, adicionalmente, están preocupadas porque el esposo perdió o podría perder su fuente de ingresos, sin embargo, la implicación mayor de estos datos es que se acabó la era en la que las mujeres no se reconocían como agentes centrales de los procesos económicos, hecho que ahora debe reconocerse en todo modelo económico de desarrollo y en toda política social.

Otra categoría que mostró diferencias significativas es la de "perder libertad de acción”, cuyos resultados totales según sexo fueron mayores en 12.8 puntos porcentuales en las mujeres en relación con el de los hombres (20.6\% y $7.8 \%$ ). En el contexto de la pandemia, como ya se explicó, las jornadas de trabajo doméstico se han intensifica- do, las labores de cuidado de los enfermos recaen en las mujeres, se realizan actividades adicionales relacionadas con la educación para los hijos, por otra parte se asume la labor de desinfectar, cocinar y mantener las relaciones familiares a distancia; de ello se deriva que los porcentajes de afectaciones por miedo, incertidumbre y estrés sean más altas para las mujeres, $11.3 \%$, que para los hombres, 7.8 por ciento.

Otro punto significativo según sexo permite ver un contraste respecto a la "necesidad de socializar" entre las mujeres y los hombres jóvenes (16.1\% y $5.0 \%$ ), se entiende porque a esta edad las jóvenes adquieren un nivel educativo mayor que les permite una participación social y política más amplia y es cuando, a través de la socialización, establecen relaciones de noviazgo y casamiento que crean cauces en sus vidas.

En cuanto a las preocupaciones hacia el futuro, los entrevistados proyectaron hacia el porvenir la mayor parte de sus percepciones del presente, con respuestas referidas al trabajo y a la economía, de 33\% del total de hombres -que aumenta en el caso de los hombres jóvenes a 36.7\%-, ambos rebasados por un porcentaje mayor en las mujeres (38.8\%); esto se debe, sin duda, a los mismos motivos que se señalaron en el párrafo anterior. Además, sobresale en el cuadro el porcentaje de las mujeres preocupadas por el hecho de que recaiga en ellas todo el peso de actividades adicionales de salud, educación y cuidado de enfermos, en relación con el trabajo en el hogar (13.3\%), respuesta que está prácticamente ausente entre los hombres, como se mencionó con anterioridad, un solo hombre se refirió a este tema.

En conclusión, tres procesos emergentes destacan en la encuesta de percepciones sobre la pandemia: el primero es el desconcierto que todavía afecta la expresión de las experiencias y sentimientos en cuanto a que faltan palabras para explicarla; las ideas para construir un nuevo pacto social y ecológico, y el tiempo para discutir y encontrar visiones de conjunto se está generando día a día. Ha sido tal la degradación del debate público en México que las disputas se ciñen 
únicamente a buscar culpables, a repetir hasta la saciedad las mismas consignas políticas y a exacerbar lo negativo, tendencia plenamente apoyada por los medios y las redes sociales.

Segundo, el manejo de la pandemia será difícil a menos de que se reconozcan los impactos diferenciales que está teniendo la pandemia en los hombres y en las mujeres por grupos de edad. Se requiere que tanto las acciones del gobierno como las de los ciudadanos tomen en cuenta estos diferenciales.

Tercero, la encuesta muestra que una de las características de las afectaciones por la pandemia es que operan en forma de rizomas, es decir, de redes complejas en las que un factor afecta a otro que, a su vez, afecta a otro que se revierte sobre los primeros. Se requieren métodos de investigación basados en la complejidad para captar un fenómeno que avanza al mismo tiempo en todos los frentes.

Ante la actual urgencia de la pandemia, atravesada por la urgencia de la sustentabilidad, el primer paso es entender cómo están siendo afectados distintos grupos y cuál es su percepción de los sucesos. Tomará mucho tiempo crear, aclarar ideas y perspectivas que ofrezcan verdades sobre las cuales fincar una visión de conjunto.

\section{Fuentes consultadas}

Gobierno de México (2021), Datos Abiertos Dirección General de Epidemiología, <https://bit.ly/3zesziY>, fecha de consulta, 30 de diciembre de 2020.

Grover, Natalie y Sample, Ian (2021), "Many 'Iong COVID' sufferers unable to fully work six months later", The Guardian, 5 de enero de 2021, Guardian News \& Media Limited, <https://bit.ly/34hfeZ6>, 10 de enero de 2021.

Heady, Patrick y Barbara Pieta (2020), "Strong families and infection: European kinship and the Coronavirus", ponencia presentada en el Royal London Anthropological Institute de Londres, 16 de julio de 2020, Royal Anthropological Institute.

Inegi (Instituto Nacional de Estadística y Geografía) (2020), Censo de Población y Vivienda 2020. Panorama sociodemográfico de Morelos, Ciudad de México, Inegi.

Lewis, Oscar (1960), Tepoztlán, Village in México, Nueva York, Rinehart and Winston, Inc.

Mendenhall, William; Beaver, Robert J. y Beaver, Barbara M. (2010), Introducción a la probabilidad y estadística, Ciudad de México, Cengage Learning Editores.

Rosas, María (1997), Tepoztlán: crónica de desacatos y resistencia, Ciudad de México, Ediciones Era.

Vázquez Conde, Daniel Salvador (2020), Don Jesús Conde Rodríguez: un tepozteco visionario, Ciudad de México, Ediciones Versalles.

Recibido: 12 de abril de 2021. Reenviado: 12 de abril de 2021. Aceptado: 30 de abril de 2021. 


\section{Lourdes Arizpe}

Antropóloga social mexicana, maestra por la Escuela Nacional de Antropología de México, y doctora en Etnología por la Escuela de Economía de Londres. En sus trabajos de campo fue pionera en los estudios sobre migración, culturas indígenas, mujeres campesinas $\mathrm{y}$, posteriormente, en los estudios sobre cambio global, desforestación y políticas culturales, tanto nacionales como internacionales. Fue presidente del Colegio Nacional de Etnólogos y Antropólogos de México y de la Unión Internacional de Ciencias Antropológicas y del Consejo Internacional de Ciencias Sociales, así como miembro de la Comisión de Naciones Unidas sobre Cultura y Desarrollo y directora adjunta para la Cultura en la Unesco. Participó como miembro del Consejo Académico del Foro Económico Global de Davos y Presidente de la Junta de Gobierno del Instituto de Naciones Unidas para el Desarrollo Social en Ginebra, Suiza. En Naciones Unidas fue miembro de "Las personas eminentes en el diálogo de las civilizaciones". Fue profesora distinguida de la Cátedra Andrés Bello del Centro Rey Juan Carlos de la Universidad de Nueva York y miembro de la Junta de Gobierno de la Biblioteca de Alejandría en Egipto; condecorada con la Orden de las Palmas Académicas de Francia, con la Medalla al Mérito Académico de la Universidad Veracruzana de México y doctora Honoris Causa de la Universidad de Gainesville, Florida, Estados Unidos de América. Sus publicaciones más recientes son Vivir para crear historia. Antología de estudios sobre desarrollo, migración, género e indígenas, Ciudad de México, CRIM/UNAM-Porrúa (2015) y Cultura, transacciones internacionales $y$ el Antropoceno, Ciudad de México, CRIM/ UNAM-Porrúa (2019), publicado en inglés por Springer-MacMillan.

\section{Esaú Bello Campos}

Licenciado en Ciencias Políticas por la Facultad de Derecho y Ciencias Sociales de la Universidad Autónoma del Estado de Morelos; desde 2016 participa en programas como: Jóvenes investigadores del estado de Morelos, la Comisión de participación ciudadana y reforma política del Honorable Congreso del Estado de Morelos y Seminario de universitarios de la Universidad Autónoma del Estado de Morelos. En 2020 participó en la elaboración del Programa interno de Protección Civil de la Facultad de Derecho y Ciencias Sociales de UAEM.

\section{Leopoldo Núñez Fernández}

Maestro en Demografía por el Colegio de México. Es investigador del Centro Regional de Investigaciones Multidisciplinarias de la Universidad Nacional Autónoma de México (CRIM-UNAM), adscrito al programa de Estudios de Población. Desde 1978 ha participado en el Diseño de diversas encuestas a nivel nacional y en el Censo de Población y Vivienda, 2010. Entre sus publicaciones más recientes están, en coautoría: "Uso del condón de los adolescentes según las características de la pareja sexual" (coautor) en Probabilidad, estadísticas y sus aplicaciones, Puebla, Fomento editorial BUAP (2018); Encuesta Intercensal 2015 (coord.), Inegi (2016); "Principales resultados del Censo de Población y Vivienda 2010" (coord.), Inegi (2012). 


\section{Sara González Gutiérrez}

Licenciada en Relaciones Internacionales por la Universidad Nacional Autónoma de México y consultora en la agencia Espiral Consultora; desde 1995 se ha vinculado en los diversos procesos, elaboración de cuestionarios, programas de captura, capacitación y supervisión en campo hasta el procesamiento y análisis de las encuestas. Entre sus publicaciones se encuentran, en coautoría "la salud reproductiva de los estudiantes de educación secundaria y media superior de San Luis Potosí", Ciudad de México, CRIMUNAM (2008); "La salud reproductiva de los estudiantes de educación secundaria y media superior en Chiapas, Guanajuato, Guerrero, San Luis Potosí y Puebla", Ciudad de México, Fundación David \& Lucile PackardCRIM-UNAM (2006).

\section{Isis Saavedra Luna}

Profesora-investigadora titular de la Universidad Autónoma Metropolitana unidad Xochimilco, miembro nivel I del Sistema Nacional de Investigadores y, desde 2019, directora de Veredas, Revista del Pensamiento Sociológico de la misma universidad. Estudió Sociología e Historia en la UAM Xochimilco y en la Universidad Nacional Autónoma de México, respectivamente; es maestra en Historia de México por la UNAM y doctora en Ciencias Sociales con especialidad en Comunicación y Política por la UAM Xochimilco. Los últimos 20 años su línea de investigación ha tenido como eje principal el estudio del cine y la imagen desde las Ciencias Sociales, así como el mundo rural y la cultura visual, ha publicado Cuando el western cruzó la frontera. Un acercamiento transdisciplinario, Ciudad de México, Universidad Autónoma Metropolitana (2016); "Entre la ficción y la realidad: Fin de la industria cinematográfica mexicana. 1989-1994", Versión, número 23, Ciudad de México, UNAM, pp. 257-260 (2007) y La literatura chicana: un compromiso social (1965-1975), Ciudad de México, Centro de Enseñanza para Extranjeros/UNAM (1993). 
